\title{
Evaluation of Cell-Penetrating Peptides as Mucosal Immune Enhancers for Nasal Vaccination
}

\author{
Yadira Lobaina ${ }^{1,5} \cdot$ Dioslaida Urquiza $^{2} \cdot$ Hilda Garay $^{3} \cdot$ Yasser Perera $^{4,5} \cdot$ Ke Yang $^{5}$
}

Accepted: 29 September 2021 / Published online: 13 October 2021

(c) The Author(s), under exclusive licence to Springer Nature B.V. 2021

\begin{abstract}
Cell-penetrating peptides (CPPs) have been evaluated as enhancers in drug delivery, their addition in medical formulations favors drug absorption allowing obtaining the pharmacological effect with lower doses. In vaccine formulations their inclusion has been also explored with interesting results. Currently mucosal vaccination constitutes a promising alternative with the main advantage of inducing both systemic and mucosal immune responses, which are crucial for control tumors and infections at mucosal tissues. In the present work the nasal immune-enhancing effect of four CPPs was evaluated in Balb/c mice. Animals were intranasally immunized with CPP and the recombinant hepatitis B surface protein ( $\mathrm{HBsAg})$ as model antigen. The antibody response in sera and mucosal tissue was measured by ELISA. The IFN- $\gamma$ secretion response at spleen was also evaluated by ELISPOT and ELISA. Among the CPPs studied one novel peptide stand out by its ability to potentiate the humoral and cellular immune response against the co-administered antigen. Considering that the use of mucosal routes is a promising strategy in vaccination, which are gaining special relevance nowadays in the development of novel candidates against SARS-CoV-2 and other potential emerging respiratory virus, the searching and development of safe mucosal adjuvants constitute a current need.
\end{abstract}

\section{Graphic Abstract}

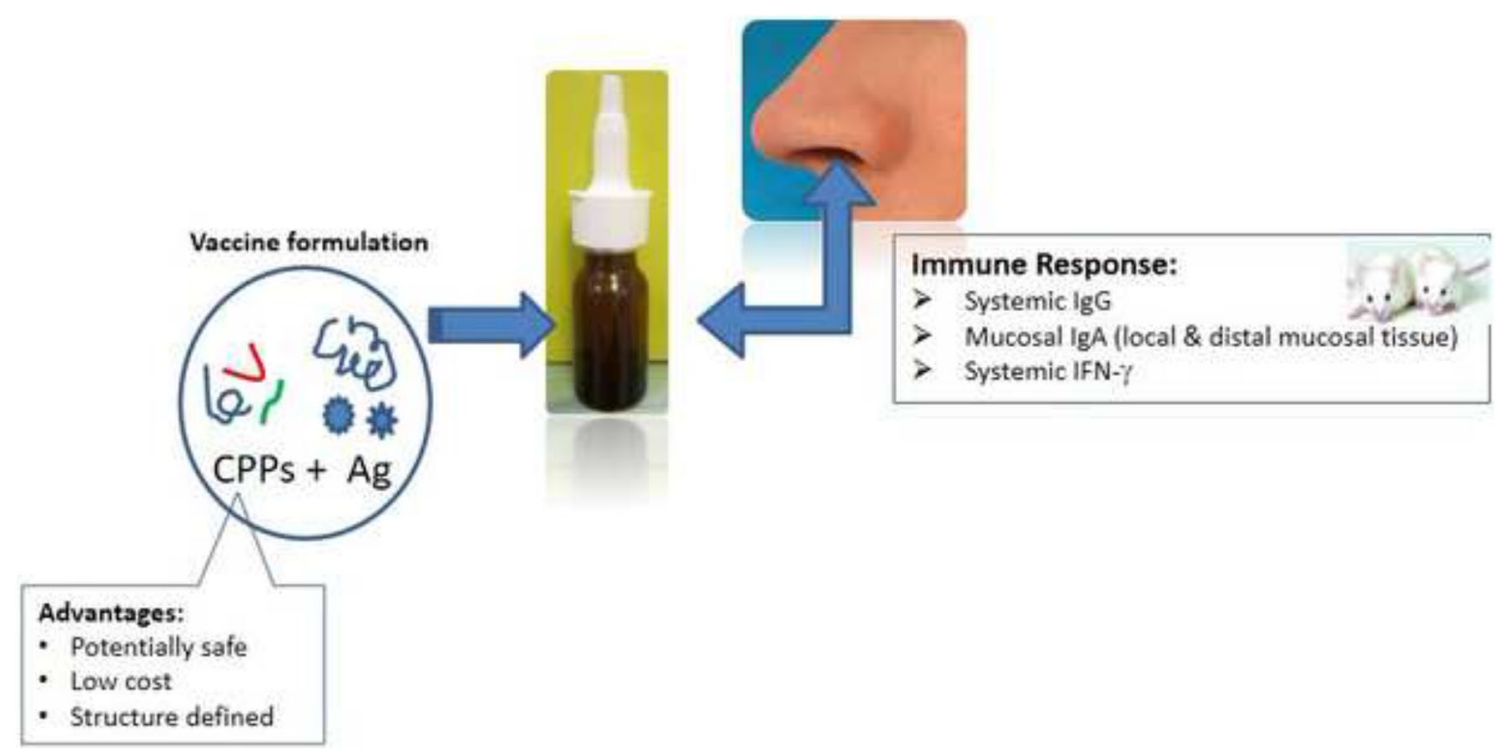

Keywords Cell-penetrating peptides $\cdot$ Nasal vaccination $\cdot$ Mucosal $\cdot$ Immune enhancer $\cdot$ Adjuvant

Extended author information available on the last page of the article 


\section{Introduction}

Currently, mucosal vaccination constitutes a compelling strategy for infectious diseases and cancer due to its several advantages: is able to induce both systemic and mucosal immune responses, differing from parenteral immunization that mainly induces a systemic response (Kraehenbuhl and Neutra 2013), mucosal tissues cover a wide surface area $\left(\sim 400 \mathrm{~m}^{2}\right.$ in a human adult) (Kraehenbuhl and Neutra 2013), and approximately $80 \%$ of total immune cells in a healthy adult are associated to mucosal surfaces (Czerkinsky and Holmgren 2010). In addition to other advantages related with needle-free administrations. Although, only one commercialized nasal vaccine has been described so far (FDA Information Regarding FluMist Quadrivalent Vaccine 2019), there are several clinical trials and research applying this route to vaccine delivery (Al Mahtab et al. 2018; Lobaina and Michel 2017; Bomsel et al. 2011; Brekke et al. 2014; Iglesias 2018; Thorstensson et al. 2014). Furthermore, nasal administration seems to be a promising strategy to improve the performance of cancer vaccines (Nizard et al. 2014, 2017; Sandoval et al. 2013). Nowadays the relevance of this route has been highlighted in the development of vaccines against respiratory virus. The current coronavirus pandemic has imprinted an unprecedented boost in vaccine research and has recalled the significance of generate an effective immune response at the portal of entry to reduce viral infection and transmission (Russell et al. 2020).

However, the search for effective and safe mucosal vaccine adjuvants remains as a research focus. The general characteristics of the mucosal tissues, and specifically nasal mucosa (Lobaina 2019), limit the use of certain established adjuvants like aluminum salts; and favor the employment of other variants like bacterial toxins and viral vectors (Kraehenbuhl and Neutra 2013; Nizard et al. 2014; Rosenthal et al. 2015). Currently, with the boom of nanotechnology, several nano-carrier systems have emerged as promising options (Marasini et al. 2017). Otherwise, cell penetrating peptides (CPPs), described more than twenty years ago as peptide sequences with the ability to potentiate the entrance to cells, constitute an appealing alternative. Due to its intrinsic characteristics these peptides are able to enhance drug delivery and improve cellular uptake of other molecules, conjugated or not (Heitz et al. 2009). CPPs are mostly peptides of less than 30 amino acids, polycationic (basically comprising clusters of polyarginine), or amphipathic (Heitz et al. 2009).

The first CPP was discovered in 1994 and called penetratin (RQIKIYFQNRRMKWKK), a 16-mer-peptide coming from the homeodomain of Antennapedia (Derossi et al. 1994). A few years later the CPP Tat (YGRKKRRQRRR) was identified as a derived sequence from an HIV-1 protein (Vives et al. 1997). Many other CPPs able to activate the movement of a cargo through the cell membrane have been identified or designed since then (Heitz et al. 2009). In line with this, the cell-penetrating capacity of the $\mathrm{LALF}_{32-51}$-derived peptides, comprising the amino acids 35 to 51 of the Limulus antilipopolysaccharide (anti-LPS) factor (LALF), was recently reported (GuerraVallespi et al. 2015). Previously the $\operatorname{LALF}_{32-51}$ peptide (HYRIKPTFRRLKWKYKGKFW) was described to bind and neutralize LPS-mediated activities, showing antiinflammatory properties and also exhibiting antiviral activity mediated by the induction of $\alpha$ and $\gamma$ interferons (Vallespi et al. 2000). Currently, a second generation of LALF $_{32-51}$-derived peptides has been studied for its antitumor effect (Guerra-Vallespi et al. 2015; Astrada et al. 2018). Furthermore, based on its cell penetrating ability, a recombinant fusion protein containing the $\mathrm{LALF}_{32-51}$ peptide conjugated to E7 antigen from HPV-16 has been evaluated, by parenteral route, as a novel vaccine candidate for the treatment of HPV related malignancies (Granadillo et al. 2011, 2017).

In spite of the increasing interest on CPPs research for medical applications, mainly in cancer topics, currently there are no FDA approved CPP-conjugated drugs (Habault and Poyet 2019; Tripathi et al. 2018). However, more than 25 CPP-conjugated drugs are under clinical evaluation for multiple uses and others are in preclinical studies (Habault and Poyet 2019). Although, its employment in vaccine formulations, with the aim to booster the immune response, constitute a more recently strategy (Brooks et al. 2010). So far, there are some promising results using CPPs as vaccine adjuvants (Granadillo et al. 2011; Belnoue et al. 2016; Brooks et al. 2018; Rostami et al. 2018; Muto et al. 2016). In the present work the adjuvant effect by intranasal route of four CPPs (Penetratin, modified- Penetratin, Tat and $\mathrm{LALF}_{32-51}$ ) formulated with the hepatitis B surface antigen was comparatively evaluated for the first time. The antigenspecific antibody and cellular immune response elicited by each preparation was measured at mucosal and systemic compartments. The obtained results support the employment of CPPs as alternative immune-enhancers for nasal vaccines, and also promote the screening of other similar compounds and derived formulations.

\section{Materials and Methods}

\section{Peptides and Antigen}

The general description of the evaluated CPPs is shown on Table 1. Peptides were synthesized by solid phase synthesis 
Table 1 Main characteristics of the CPPs evaluated

\begin{tabular}{llll}
\hline CPP & Amino acid sequences (n) & Original source & Nature \\
\hline Tat & GRKKRRQRRRPPQ (13 aas) & HIV virus & $\begin{array}{l}\text { Nonamphipathic } \\
\text { (highly cationic) }\end{array}$ \\
Penetratin & RQIKIWFQNRRMKWKK (16 aas) & $\begin{array}{c}\text { Drosophila Antennapedia } \\
\text { homeodomain }\end{array}$ & Secondary amphipathic \\
mod-Penetratin & RQIkIWFQNRRMkWkK (16 aas) & C \\
LALF $_{32-51}$ & HYRIKPTFRRLKWKYKGKFW (20 aas) & Limulus polyphemus & Primary amphipathic \\
\hline
\end{tabular}

The aas represented in bold lower case correspond to D-aas. The sites of substitutions correspond to theoretical trypsin susceptibility, according to an analysis at Peptide Cutter-Expasy database

and purified using reverse-phase-HPLC to $>99 \%$ purity on an acetonitrile $/ \mathrm{H}_{2} \mathrm{O}$ trifluoroacetic acid gradient (Peptide Synthesis Lab, CIGB, Cuba). The peptide identity was confirmed by ion-spray mass spectrometry (Micromass, Manchester, UK). All CPPs were C-terminal amidated to increase its stability against in vivo proteolytic degradation. Apirogenic water (Biochrom AG, Alemania) with $1 \%$ dimethyl sulphoxide (DMSO) (Sigma, USA) was employed to reconstitute the lyophilized peptides.

The HBsAg, subtype $a d w 2$ was expressed and purified from Pichia pastoris yeast at $>95 \%$ purity (CIGB, Havana, Cuba) as ingredient of the commercial anti-hepatitis B prophylactic vaccine Heberbiovac-HB (Hardy et al. 2000).

\section{Mice and Immunization Schedule}

$\mathrm{Balb} / \mathrm{c}$ female mice (H-2d haplotype) of 8 to 12 weeks were used (CENPALAB, Havana, Cuba). Groups of six animals each were immunized with four doses administered weekly by intranasal route. Each dose contains $2 \mathrm{mM}$ of $\mathrm{CPP}+5 \mu \mathrm{g}$ $\mathrm{HBsAg}$ in a final volume of $25 \mu \mathrm{L}$. As controls groups, mice immunized with, $5 \mu \mathrm{g}$ HBsAg in PBS intranasally (group $5), 5 \mu \mathrm{g}$ HBsAg adjuvated in alum $(0.5 \mathrm{mg} / \mathrm{mL})$ by intramuscular route (group 6), and saline solution (group 7) were used. All the immunogens were dissolved in sterile PBS. For nasal administrations, mice were anesthetized by intraperitoneal injection using $30 \mu \mathrm{L}$ ketamine $(50 \mathrm{mg} / \mathrm{mL})$, placed in a supine position and the immunogens $(25 \mu \mathrm{L})$ were dispensed slowly, alternating the nostril, using a pipette tip. For intramuscular route the immunogen was administered in a final volume of $100 \mu \mathrm{L}$. The dose of CPP and antigen evaluated in this work was selected based on previous experiences (Muto et al. 2016; Lobaina et al. 2010).

Mice were maintained at animal facilities under specific-pathogen-free conditions (CIGB, Cuba). All protocols were reviewed and approved by the institutional animal care committees in compliance with Regulation No. 39/04 of the Cuban Regulatory Agency (CECMED) and the European regulations on Animal Welfare.

\section{Biological Fluids}

The blood was collected by retro-orbital puncture. Samples were centrifuged at $7800 \mathrm{~g}$ for $10 \mathrm{~min}$ (centrifuge 5415C, Eppendorf, Hamburg, Germany). The obtained sera were stored at $-20{ }^{\circ} \mathrm{C}$ until evaluation. Vaginal washes were obtained by a skilled technician to avoid trauma and blood contamination. They were obtained by reflushing $100 \mu \mathrm{L}$ of a sterile PBS solution with a micropipette. The collected lavages were centrifuged as above, and the supernatant stored at $-20{ }^{\circ} \mathrm{C}$.

\section{ELISAs}

Anti - IgG, -IgA ELISAs were carried out as previously described (Lobaina et al. 2010). Briefly, the plates were coated with $5 \mu \mathrm{g} / \mathrm{mL}$ of HBsAg and blocked with $2 \%$ skim milk solution. Samples were evaluated in duplicates using different dilutions starting from $1 / 50$ for sera. Vaginal lavages were assayed directly, without dilution. Specific horseradish peroxidase conjugates (Sigma, USA) were employed and OPD (Sigma, USA)/hydrogen peroxide substrate solution was used. After 15 min of incubation, the reaction was stopped using $2 \mathrm{~N}$ sulfuric acid and the optical density (O.D) was read at $492 \mathrm{~nm}$ in a multiscan (SUMA, Cuba). In the case of the antibody responses measured in sera data was represented in the graphics as $\log 10$ titers. The arbitraric units of titers were calculated by plotting the O.D values obtained for each sample in a standard curve (an hyper-immune sera of known titer). On the other hand, in the case of the antibody response measured in mucosal lavages, the positive signals obtained are usually lower and there isn't a standard available, therefore the results were represented as O.D at $492 \mathrm{~nm}$.

\section{IFN- $\gamma$ ELISPOT and ELISA}

IFN- $\gamma$ ELISPOT assay was performed using a Mouse IFN- $\gamma$ ELISpot kit (Mabtech, Sweden). Ten days after the last 
immunization (4th dose) the splenocytes were isolated in RPMI culture medium (Gibco, EU). The samples (five mice per group) were processed individualized, with the exception of the control groups (HBs in alum and Placebo) which were processed as pooled samples of three randomly selected mice. Duplicates cultures $\left(2 \times 10^{5}\right.$ and $5 \times 10^{5}$ splenocytes per well) were settled, for $48 \mathrm{~h}$ at $37{ }^{\circ} \mathrm{C}, 5 \% \mathrm{CO}_{2}$, in a 96 well round-bottom plate with $10 \mu \mathrm{g} / \mathrm{mL}$ of $\mathrm{S}_{28-39} \mathrm{CTL}$ peptide (IPQSLDSWWTSL) from HBsAg (Schirmbeck et al. 1998), $10 \mu \mathrm{g} / \mathrm{mL}$ of ConA, or medium. After, the whole content of this plate was transferred to an ELISPOT pre-coated plate and incubated for $16-20 \mathrm{~h}$ at $37{ }^{\circ} \mathrm{C}, 5 \% \mathrm{CO}_{2}$. The incubations with the detection conjugated antibodies and following steps were done as recommended by the producers. An AELVIS ELISPOT reader were used for spots count.

In parallel, a similar 96 well round-bottom plate were incubated for measure by ELISA the IFN- $\gamma$ secretion at culture supernatant. With this aim an IFN- $\gamma$ standard and the same antibody pair (Mabtech, Sweden) were used.

\section{Statistical Analysis}

For statistical analyses the GraphPad Prism version 5.00 statistical software (Graph-Pad Software, San Diego, CA, USA) was used. All titers were transformed to $\log 10$ for a normal distribution. For the non sero-converting sera, an arbitrary titer of 1:50 was assigned for statistical processing. The One-way Anova test followed by a Tukey's post-test was used as parametric tests for multiple groups comparisons. In case of non- parametric multiple comparisons, the Kruskal Wallis test and Dunns post-tests was employed. A standard $\mathrm{P}$ value consideration was followed, ${ }^{\mathrm{ns}} \mathrm{p}>0.05 ; * \mathrm{p}<0.05$; $* * \mathrm{p}<0.01 ; * * * \mathrm{p}<0.001$.

\section{Results and Discussion}

\section{Systemic IgG Antibody Response}

To study the immune enhancer capacity of each evaluated CPPs mice were intranasally immunized with a mix of HBsAg, as model antigen, and each CPP described in Table 1. Immunogens were administered in four doses, weekly, and the sera were collected five days after each dose for $\mathrm{IgG}$ response evaluation. The humoral immune response results are representative of two independent experiments.

After the second dose, for the evaluated intranasal immunized groups, anti-HBs positive IgG response was only detected in $1 / 6$ animals from the group that received Penetratin, and 2/6 in the group immunized with LALF peptide (Fig. 1a). On the other hand, in the positive control group, that received HBsAg in alum by intramuscular route, all animals showed positive responses with titers $\geq 10^{3}$. However, after the third dose (Fig. 1b), all animals from the groups receiving Penetratin and LALF seroconverted, differing from the rest of intranasally immunized groups in which only few animals seroconverted. The IgG titers detected for these two groups were statistically similar, and significantly superior $(p<0.001)$ to the response generated by the other nasally immunized groups (Tat, mod-Pen and HBsAg in PBS). The $\mathrm{IgG}$ response obtained for the last three groups was not statistically different from the placebo group. Later on, after the fourth dose (Fig. 1c), the groups immunized with Penetratin and LALF showed an IgG response which only was significantly superior to the generated by the groups immunized with Tat and placebo. However, the $\mathrm{IgG}$ response generated by the two former groups reached values more closer to the obtained for the alum adjuvated control group $(\mathrm{p}<0.05)$.
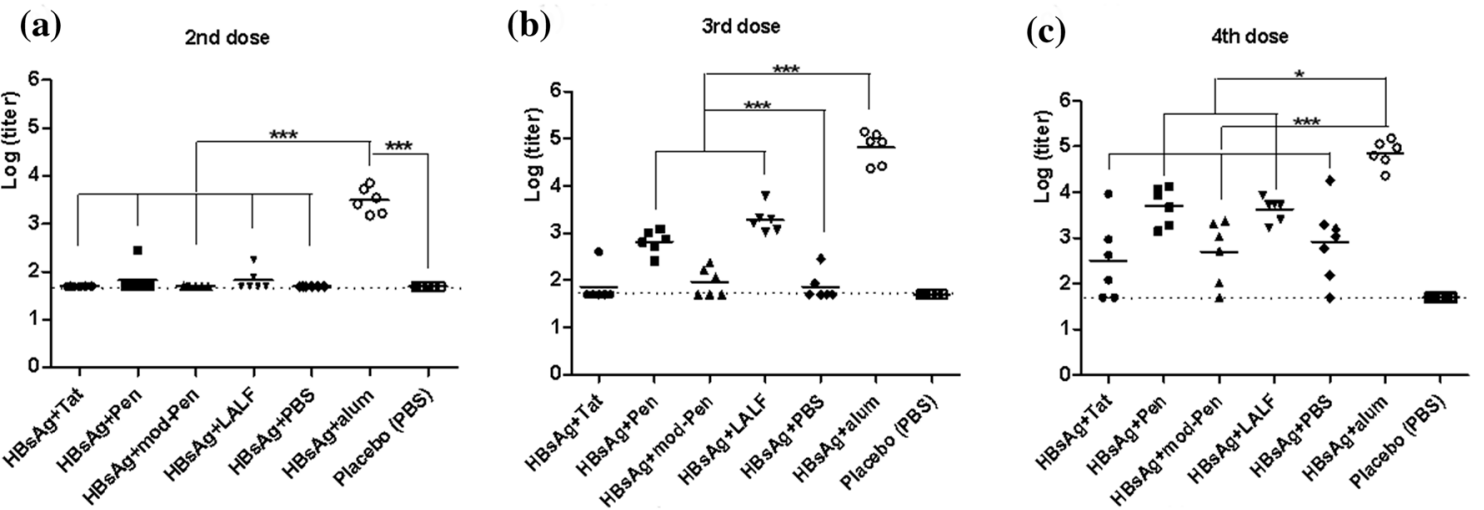

Fig. 1 Anti-HBsAg IgG antibody measured in sera following a two, b three, and $\mathbf{c}$ four doses. Six mice per group where nasally immunized with $5 \mu \mathrm{g}$ HBsAg plus $2 \mathrm{mM}$ of each individual CPP [Tat, Penetratin (Pen), modified-Penetratin (mod-Pen) and $\left.\mathrm{LALF}_{32-51}\right]$ or PBS. Two control groups were included, $5 \mu \mathrm{g}$ HBsAg in alum by intramuscular route, and nasally administered PBS (Placebo). Statistical differences were represented using standard terminology 
Considering that the generation of a Th1 pattern of immune response would be of interest for several vaccine candidates and the fact that the induction of IgG2a subclass in mice correlates with this kind of response (Snapper and Paul 1987) the HBs-specific IgG2a antibody response was evaluated after the last dose (Fig. 2). Among the groups receiving $\mathrm{CPPs}+\mathrm{HBsAg}$, the higher anti-HBs IgG2a response was obtained for the immunized with Penetratin and LALF, without significant differences between them, neither with the group immunized in alum by intramuscular route, nor with the group receiving HBsAg in PBS by intranasal route. The $\mathrm{IgG} 2 \mathrm{a}$ response induced by the groups immunized with Tat and mod-Penetratin was similar to that one from the placebo group, and significantly lower than the generated by the first three groups mentioned above.

The IgG results after three doses demonstrate a clear immunoenhancing capacity by nasal route for two out of four CPPs evaluated, Penetratin and LALF. This result is even more relevant if we consider that the antigen selected for the

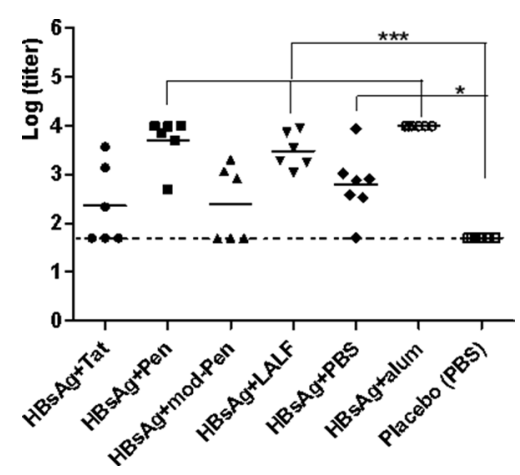

Fig. 2 Anti-HBsAg IgG2a antibody response measured in sera after four doses. Groups of six mice where nasally immunized with $5 \mu \mathrm{g}$ HBsAg plus $2 \mathrm{mM}$ of each individual CPP [Tat, Penetratin (Pen), modified-Penetratin (mod-Pen) and $\mathrm{LALF}_{32-51}$ ] or PBS. Two controls group were included, $5 \mu \mathrm{g}$ HBsAg in alum by intramuscular route, and nasally administered PBS (Placebo). Statistical differences were represented using standard terminology study is per se highly immunogenic by nasal route (Lobaina et al. 2005), which increases the threshold to overcome. This fact was even evident after the fourth dose, where the groups immunized with Penetratin and LALF still showed a trend to induce a higher HBs-specific IgG response compared with the control of HBsAg in PBS.

The results obtained using Penetratin as immune enhancer by nasal route are in line with a previously reported work, where this CPP shows a similar capacity to enhance the antibody immune response when administered with two different antigenic models, OVA and Influenza A (Muto et al. 2016). However, the results obtained here for the modified Penetratin variant were unexpected. Based on the results reported by Muto and cols (Muto et al. 2016), the complete D-aas variant of Penetratrin shows a much better immuneenhancer capacity compared with its L- variant. In our case, considering the production cost that represents the complete $\mathrm{D}$-aas variant, we decided to introduced $\mathrm{D}$-aminoacids only in the positions theoretical predicted as more susceptible to trypsin cleavage. Nevertheless, our results with the modified Penetratin variant were worse than the obtained for its L-counterpart. For future studies we suggest to study the in vivo stability of Penetratin in nasal mucus, to determine which specific aas can be substituted for D-aas to improve the enhancing capacity, and if it is possible to do that without an all-D peptide variant.

\section{Antibody Response at Vaginal Mucosa}

It is recognized that immune stimulation through the nasal mucosa is able to induce an antibody response (mainly IgA) at distal mucosal tissues, being significant the response elicited at vaginal mucosa (Johansson et al. 2001). Based on this fact, the anti-HBsAg IgA and IgG response was studied at vaginal lavages after four doses. As show in Fig. 3a, a trend to elicited a higher IgA response were observed for the groups immunized whit Penetratin and LALF, although no statistical differences were detected among all evaluated
Fig. 3 Anti-HBsAg antibody response measured at vaginal lavages after four doses. a $\operatorname{Ig} \mathrm{A}$, b IgG. Groups of six mice where nasally immunized with $5 \mu \mathrm{g}$ HBsAg plus $2 \mathrm{mM}$ of each individual CPP [Tat, Penetratin (Pen), modified-Penetratin (mod-Pen) and $\mathrm{LALF}_{32-51}$ ] or PBS. Two controls group were included, $5 \mu \mathrm{g}$ HBsAg in alum by intramuscular route, and nasally administered PBS (Placebo). No statistical differences were detected (a)

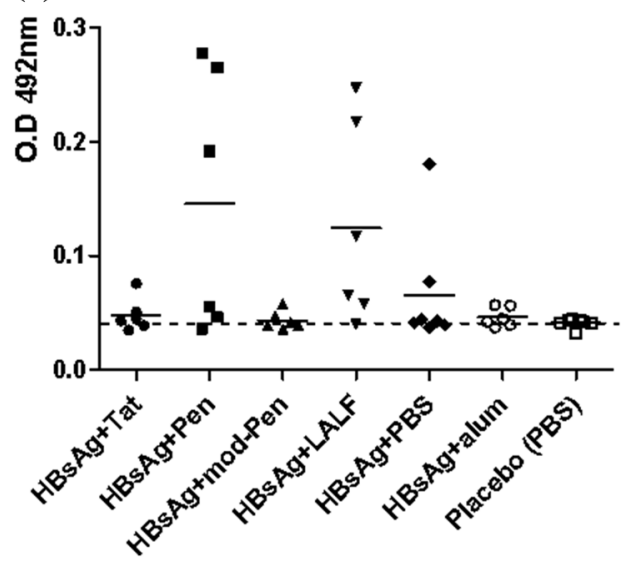

(b)

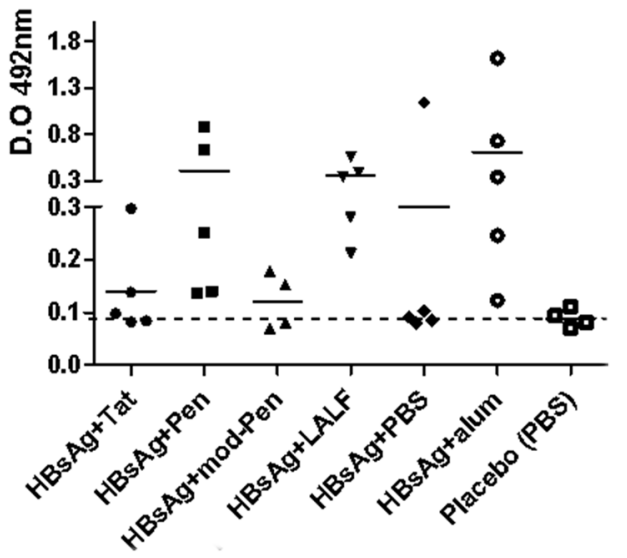


treatments. As expected, the positive control group immunized by intramuscular route was unable to induce a detectable $\operatorname{IgA}$ response at vaginal mucosa. This behavior is in line with the current knowledge indicating that to efficiently induce an immune response at mucosal surfaces a mucosal delivery route should be used (Kraehenbuhl and Neutra 2013).

The IgG response results obtained in vaginal lavages (Fig. 3b) followed a general pattern similar to that of IgA, with the exception of the response elicited by the group immunized in alum by intramuscular route, which showed a marked trend to develop a higher reaction. However, no statistical differences were detected among all evaluated treatments. This could be explained by the passive transudation into vaginal mucosal tissue of part of the high $\mathrm{IgG}$ systemic immune response generated by the intramuscular injection of four doses of HBsAg in alum. Generally, the levels of $\operatorname{IgG}$ found it at mucosal secretions are a reflex of the systemic IgG response that reach the tissue by transudation, differing from the IgA antibody response which is mainly generated after a mucosal inductive site stimulation (Kraehenbuhl and Neutra 2013). Both antibody classes contribute to the protection of mucosal surfaces.

\section{IFN- $\gamma$ Secretion Response by Splenic CD8 T Cells}

In this study the effect of the evaluated CPPs in terms of improve the cellular immune response against co-administered antigens was also explored. With this aim the HBsspecific IFN- $\gamma$ secretion in spleen cells by ELISPOT after the fourth dose was measured (Fig. 4). Surprisingly, the group immunized with Tat, which showed a weak antibody response in sera, generated a clearly positive response in all the evaluated animals (5/5). The second better response was obtained for the group immunized with LALF where 4/5 mice respond positively, following by mod-Penetratin with $2 / 5$, and Penetratin $1 / 5$. On the other hand, the control group immunized with HBsAg in PBS intranasally showed a positive response in $3 / 5$ mice. This last result correlates with previous data reported showing that the HBsAg in PBS by intranasal route is capable to elicit a positive IFN- $\gamma$ response at spleen of a magnitude that trends to be lower than the generated by the HBsAg in alum administered intramuscularly (Aguilar et al. 2004). Overall, although in statistics terms we did not detected significant differences among the geometric means for each evaluated group, a trend to induce a higher IFN- $\gamma$ secretion response was observed for the groups receiving Tat and LALF jointly with the HBsAg.

On the other hand, concerning the result obtained here for the group that received HBsAg adjuvated in alum by intramuscular route, as we mentioned above, this behavior is not surprising for us, other previous experiences and

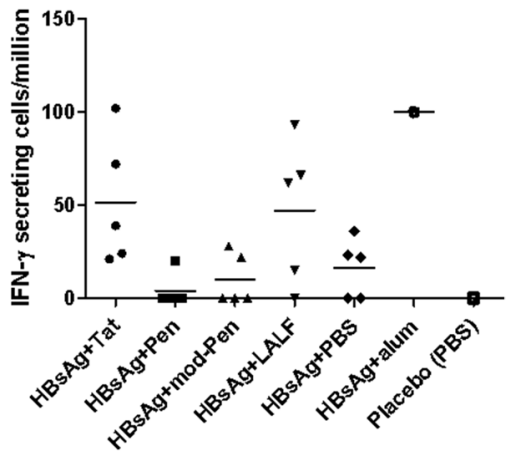

Fig. $4 \mathrm{HBsAg}$-specific IFN- $\gamma$ secretion response at spleen. The assay was carried out by ELISPOT after four doses. Six mice per group where nasally immunized with $5 \mu \mathrm{g} \mathrm{HBsAg}$ plus $2 \mathrm{mM}$ of each individual CPP [Tat, Penetratin (Pen), modified-Penetratin (mod-Pen) and $\mathrm{LALF}_{32-51}$ ] or PBS. Two controls group were included, $5 \mu \mathrm{g} \mathrm{HBsAg}$ in alum by intramuscular route, and nasally administered PBS (Placebo). No statistical differences were detected

published data (Aguilar et al. 2004) support this finding. Although alum is an adjuvant historically more associated with the promotion of antibody response, in the past years new data have arise challenging this paradigm (Lobaina et al. 2010; Iglesias et al. 2006). The evidences suggest that the pattern of immune response developed after immunization with aluminum hydroxide adjuvant is influenced by the nature of the antigens included in the formulation, showing that alum doesn't impose a tight commitment with a Th2 pattern. In this case, the antigen used is a virus-like particle, purified from Pichia pastoris, that include in its structure some glycosilations and lipids (Hardy et al. 2000). These specific features could explain the change in the classical pattern of response expected for alum adjuvated antigens and also could favor the noncovalent interactions established between the HBsAg and the different CPPs evaluated.

Furthermore, with the aim to corroborate the cellular immune response measured by ELISPOT, the IFN- $\gamma$ concentration in splenocyte's culture supernatant was also evaluated by ELISA (Fig. 5). Considering practical issues, in this assay only the groups immunized with Penetratin and LALF (based on their better performance at humoral immunity), as well as the required control groups (HBsAg in PBS and placebo) were evaluated. The obtained results were consistent with the ELISPOT data. The group immunized with LALF showed IFN- $\gamma$ response levels of variable magnitude in $4 / 5$ animals (three of them $>500 \mathrm{pg} / \mathrm{ml}$ ), while in the group immunized with Penetratin responded only $2 / 5$ animals (both with marginal values).

In general, the present work extends the knowledge regarding the use of CPPs as immune-enhancer by nasal route. As far as we know, there are only very few previous publications on that line. One of them evaluates Penetratin 


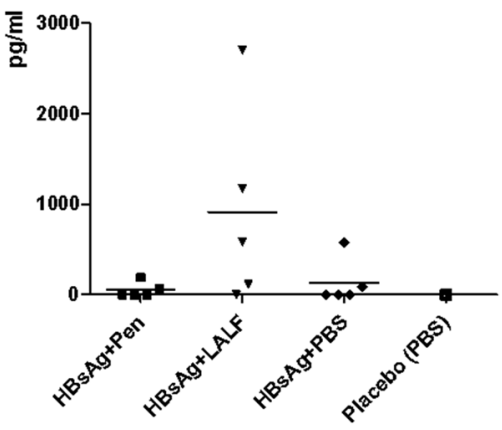

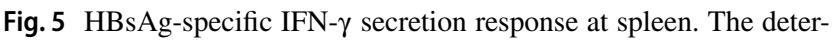
mination was carried out by ELISA in culture supernatant, after four doses. Six mice per group where nasally immunized with $5 \mu \mathrm{g}$ HBsAg plus $2 \mathrm{mM}$ of each individual CPP (Penetratin (Pen) and $\mathrm{LALF}_{32-51}$ ) or PBS. A Placebo control group (PBS nasally administered) was included. No statistical differences were detected

peptide, in its L- and D-aas variants, and is limited only to the evaluation of $\operatorname{IgG}$ response in sera and $\operatorname{Ig} \mathrm{A}$ at nasal mucosa (Muto et al. 2016). Another published work evaluates the $\mathrm{N}$-vinylacetamide-co-acrylic acid polymer linked to D-octa-arginine as mucosal delivery system (Sakuma et al. 2012). In both above mentioned works (Muto et al. 2016; Sakuma et al. 2012) the same model antigens, OVA and Influenza A, and the same response parameters readout were employed. Here we obtained, with a different antigen (a VLP), similar results to those already reported for L-Penetratin in terms of humoral response (Muto et al. 2016) and we also expanded the data to the IFN- $\gamma$ secretion response generated by splenic $\mathrm{CD} 8+\mathrm{T}$ cells. In addition, interesting information regarding a partial D-Penetratin variant (modPenetratin) was obtained, posing new questions for future studies.

On the other hand, Tat peptide, one of the classic described CPPs; due to its origin has a closer relation with vaccines. Since its identification, Tat was employed for multiple developments in biomedicine field as a tool to potentiate the transportation of cargoes into cells. Currently there are some drug and vaccine candidates, some of them in clinical phases (like the CIGB300 for cancer therapy), that employ Tat as cell penetrating enhancer (Tripathi et al. 2018; Sarduy et al. 2015; Sahay et al. 2019; Tang et al. 2012; Grau et al. 2018). Considering the present results obtained for the evaluation of Tat in a simple mix with HBsAg by nasal route, this CPP show the capacity to improve only the cellular immune response, without an impact on humoral response. This behavior, that should be evaluate using other model antigens, could be interesting in the case of infections where the development of cellular immune response correlates with protection and the generation of an antibody response could cause undesired immune-pathogenic reactions.
Early this year a work evaluating the performance of formulations based on CPPs (including the two mentioned above) linked to liposomes as delivery systems in lipopeptide vaccine candidates against Group A Streptococcus (GAS) by intranasal route was published (Yang et al. 2021). The outcome measures of this study was the antibody response in serum and its opsonic capacity. Interestingly, in this specific formulation the candidate using Tat peptide induced one of the highest antibody titers. The combination of CPPs with other strategies to develop more efficient and potent delivery systems and/or adjuvants is in the spotlight nowadays (Yang et al. 2019; Jiang 2021). Although this trend can generate new potentialities, on the other hand it increases the complexity of vaccine formulations. Considering the history of human adjuvants development and approval, and the increasing regulatory standards in biomedical industry, we think that CPPs, either conjugated or co-administered, constitute a promising option for the near future.

In our point of view, the data for the LALF peptide emerging from this work is very interesting. The humoral and cellular immune responses generated by the co-administration with LALF peptide are promising. This peptide had been previously described as immune-modulator (Vallespi et al. 2000; Granadillo et al. 2011), but the present work constitutes the first report of its use by nasal route as vaccine adjuvant. Previously, based on its cell penetrating ability, LALF peptide had been evaluated conjugated with E7 antigen from HPV-16 by subcutaneous route as a vaccine candidate for HPV associated malignancies treatment (Granadillo et al. 2011, 2017). In line with our results, the inclusion of LALF in the preparation favors the generation of cellular immune response in mice (Granadillo et al. 2011). Considering the relevance of elicit a mucosal immune response at vagina for efficiently deal with HPV infection and related malignancies, the evaluation of this vaccine candidate by the nasal route is currently ongoing by our group with encouraging results. The unpublished data with E7 protein antigen supports the ability of LALF as immune-enhancer by nasal route.

In our opinion the behavior of each CPP as non-covalent linked immune-enhancer is strongly influenced by the nature of the co-administered antigen, and the type of interaction they establish. The influence of these features is more relevant in the case of simple mix formulations of CPPs plus antigens (the variant studied in this work) than in conjugated preparations. However, the present work reproduced previous results obatined for L-Penetratin (Muto et al. 2016) as non-covalent enhancer of humoral immune response, so far evaluated with three different model antigens. The use of chemical conjugation of CPPs to antigens constitutes an established way to ensure a more stable interaction between them and therefore a higher guarantee that the cargo enters the cell. However in our experiments we decided to test, as 
first option, the simple mix formulation, considering that the nature of the antigen employed (Hardy et al. 2000) could facilitate the interaction whit the CPPs, and also based on previous reports indicating the feasibility of non-conjugated alternatives (Muto et al. 2016). In our opinion, this plain option looks more rational for the preliminary screening of multiple CPPs variants. Although we recognizes the advantages of conjugation, the process increases the complexity and costs of the vaccine production and also could introduce some changes in antigenic sites. On the other hand, we think that conjugation could potentiate the effects observed in this work and even could impact in reducing the dose. Future experiments to elucidate in more details the nature of the interactions and the effect of conjugation in the case of the more promising studied CPPs are in plans. So far we know that there are not marked differences in charge between the evaluated CPPs that could explain differences in electrostatic interactions with the HBsAg. However, we consider that the differential amphipathic character of the CPPs in study plays a key role determining its interaction with HBsAg with impact on the final outcome. As we mentioned above the HBsAg is a virus-like particle and includes some lipids in its structure (Hardy et al. 2000) which could favor the association with amphipathic compounds. Supporting this idea the good performance of primary and secondary amphipathic CPPs as non-covalent carriers, with the ability to interact preferentially with lipid membranes, had been previously described (Gros et al. 2006; Crombez et al. 2009; Deshayes et al. 2004).

Other possible explanation to the different behavior of each CPP as immune-enhancer is the specific internalization mechanisms they could followed. It is well recognized that CPPs can be internalized by endocytic and non-endocytic paths, arriving to endosomes and cytoplasm, respectively. The internalization pathway may impact directly in the type of processing and presentation to the immune system, rendering different pattern of responses (Grau et al. 2018). In general, CPPs internalization mechanisms are influenced by different parameters like sequence and concentration of the peptide, and specific features of the cargo (Madani et al. 2011). Primary and secondary amphiphatic CPPs, at low micromolar concentrations, can directly enter through the cell membrane; while non-amphiphatic CPPs mostly uses endocytosis (Ziegler 2008). However, for Penetratin cellular uptake endocytosis is the major mechanism suggested in the literature, both in the absence or presence of cargoes (Madani et al. 2011). On the other hand, the fact that LALF peptide sequence and extend is more similar to Penetratin than to Tat could support the similar behavior of the two former as humoral immune response enhancers. Otherwise, direct penetration is most probable for primary amphiphatic CPPs (Madani et al. 2011) (like LALF); this pathway could explain the high cellular immune response generated by the group immunized with LALF. However, direct penetration has been also suggested for arginine rich CPPs like Tat (Guterstam et al. 2009; Thoren et al. 2003). We hypothesized, that the dual ability of LALF to enhance humoral and cellular immunity against the co-administered antigen could also be explained by its capacity to penetrate cells by endocytosis and direct membrane transduction, using both pathways with appreciable rates. Without diminished the contribution of the immunomodulatory intrinsic properties previously described for LALF (Vallespi et al. 2000; Granadillo et al. 2011). Indeed, the use of both internalization mechanisms has been previously described for CIGB-552 (a LALF $_{32-51}$ derived peptide), although the contribution of each pathway vary among different cell lines (Astrada et al. 2018).

Regarding the concentration, we used in our experiments $2 \mathrm{mM}$ considering the findings reported by Muto and cols (Muto et al. 2016), who described it as the best evaluated for Penetratin nasal administration. This concentration is not so high if we considered that mucosal administration has different requirements, compared with parenteral, related with the several particular barriers to overcome. However, taking into account the different CPPs performance, in future studies lower concentrations should be evaluated by nasal route.

Another issue of concern in the development of vaccines and immune-enhancers is the safety of the formulation's components. Although has been widely reported that CPPs are usually nontoxic (Grau et al. 2018), a detailed study should be done case by case, exploring the intended administration route and evaluating different concentrations. The present study was not designed with this aim, however animals general conditions and behavior were observed post-immunizations and along the study and no signals of concern were detected. In addition, the low toxicity of nonamphipathic CPPs like Tat and secondary amphipathic like Penentratin has been previously reported (Madani et al. 2011). On the other hand, LALF peptide has been showed its safety in several mice studies by subcutaneous route (Guerra-Vallespi et al. 2015; Granadillo et al. 2011, 2017).

\section{Conclusions}

The present work extends the knowledge regarding the use of CPPs as immune-enhancer by nasal route. In fact, the results described here for Penetratin, LALF and Tat peptides show potentialities for their future inclusion in nasal vaccine formulations. Considering the few vaccines adjuvants approved for human's use, CPPs seem to be a promising option for the future, in view of their safety, easy production and low cost. Certainly, deeper studies regarding the use of CPPs as vaccine adjuvants by nasal and parenteral routes are need. 
Acknowledgements The publication of this work was supported by "The Science and Technology Innovation Program of Hunan Province", China, grant number 2020RC5035 and "Hunan Provincial Innovative Construction Program”, China, Grant Number 2020WK2031.

Author Contributions Idea-experimental design, YL, YP; methodology, YL, DU, HG; analysis, YL; research, YL; writing-manuscript preparation, YL; revision and edition, YL, YP; supervision, YP and KY.

\section{Declarations}

Conflict of interest The authors have no conflict of interests.

\section{References}

Aguilar JC, Lobaina Y, Muzio V, Garcia D, Penton E et al (2004) Development of a nasal vaccine for chronic hepatitis B infection that uses the ability of hepatitis B core antigen to stimulate a strong Th1 response against hepatitis B surface antigen. Immunol Cell Biol 82:539-546

Al Mahtab M, Akbar SMF, Aguilar JC, Guillen G, Penton E, Tuero A, Yoshida O, Hiasa Y, Onji M (2018) Treatment of chronic hepatitis $B$ naïve patients with a therapeutic vaccine containing HBs and $\mathrm{HBc}$ antigens (a randomized, open and treatment controlled phase III clinical trial). PLoS ONE 13(8):e0201236

Astrada S, Fernández Massó JR, Vallespí MG, Bollati-Fogolín M (2018) Cell penetrating capacity and internalization mechanisms used by the synthetic peptide CIGB-552 and its relationship with tumor cell line sensitivity. Molecules 23:801

Belnoue E, Di Berardino-Besson W, Gaertner H, Carboni S, DunandSauthier I et al (2016) Enhancing antitumor immune responses by optimized combinations of cell-penetrating peptide-based vaccines and adjuvants. Mol Ther 24(9):1675-1685

Bomsel M, Tudor D, Drillet AS, Alfsen A, Ganor Y et al (2011) Immunization with HIV-1 gp41 subunit virosomes induces mucosal antibodies protecting nonhuman primates against vaginal SHIV challenges. Immunity 34:269-280

Brekke K, Lind A, Holm-Hansen C, Haugen IL, Sørensen B et al (2014) Intranasal administration of a therapeutic HIV vaccine (Vacc-4x) induces dose-dependent systemic and mucosal immune responses in a randomized controlled trial. PLoS ONE 9(11):e112556

Brooks NA, Pouniotis DS, Tang C-K, Apostolopoulos V, Pietersz GA (2010) Cell-penetrating peptides: application in vaccine delivery. Biochim Biophys Acta Rev Cancer 1:25-34

Brooks N, Hsu J, Esparon S, Pouniotis D, Pietersz GA (2018) Immunogenicity of a tripartite cell penetrating peptide containing a MUC1 variable number of tandem repeat (VNTR) and A T helper epitope. Molecules 23:2233

Crombez L, Aldrian-Herrada G, Konate K, Nguyen QN, McMaster GK et al (2009) A new potent secondary amphipathic cell-penetrating peptide for siRNA delivery into mammalian cells. Mol Ther 17(1):95-103

Czerkinsky C, Holmgren J (2010) Topical immunization strategies. Mucosal Immunol 3(6):545-555

Derossi D, Joliot AH, Chassaing G, Prochiantz A (1994) The third helix of the Antennapedia homeodomain translocates through biological membranes. J Biol Chem 269:10444-10450

Deshayes S, Plénat T, Aldrian-Herrada G, Divita G, Le Grimellec C, Heitz F (2004) Primary amphipathic cell-penetrating peptides: structural requirements and interactions with model membranes. Biochem 43(24):7698-7706. https://doi.org/10.1021/bi049298m
FDA Information Regarding FluMist Quadrivalent Vaccine. URL:https://www.fda.gov/biologicsbloodvaccines/vaccines/appro vedproducts/ucm508761.htm. Accessed March 2019

Granadillo M, Vallespi MG, Batte A, Mendoza O, Soria Y, Lugo VM, Torrens I (2011) A novel fusion protein-based vaccine comprising a cell penetrating and immunostimulatory peptide linked to human papillomavirus (HPV) type 16 E7 antigen generates potent immunologic and anti-tumor responses in mice. Vaccine 29:920-930

Granadillo M, Batte A, Blanco A, Alfonso AB, Suárez J et al (2017) LALF32-51-E7 therapeutic vaccine induces antitumor immunity against human papillomavirus type 16 E7-expressing murine tumor metastases in the lungs. Clin Exp Metastasis 34:241-249

Grau M, Walker PR, Derouazi M (2018) Mechanistic insights into the efficacy of cell penetrating peptide-based cancer vaccines. Cell Mol Life Sci 75:2887-2896

Gros E, Deshayes S, Morris MC, Aldrian-Herrada G, Depollier J et al (2006) A non-covalent peptide-based strategy for protein and peptide nucleic acid transduction. Biochim Biophys Acta 1758:384-393

Guerra-Vallespi M, Fernández-Massó JR, Oliva-Argüelles B, ReyesAcosta O, Garay-Pérez HE et al (2015) CIGB-552: a new penetrating peptide with antitumor action mediated by the increased levels of the COMMD1 protein in cancer cell lines. Biotecnol Apl 32:3501-3505

Guterstam P, Madani F, Hirose H, Takeuchi T, Futaki S, El Andaloussi S, Graslund A, Langel U (2009) Elucidating cellpenetrating peptide mechanisms of action for membrane interaction, cellular uptake, and translocation utilizing the hydrophobic counter-anion pyrenebutyrate. Biochim Biophys Acta 1788(12):2509-2517

Habault J, Poyet JL (2019) Recent advances in cell penetrating peptidebased anticancer therapies. Molecules 24:927

Hardy E, Martínez E, Diago D, Díaz R, González D, Herrera L (2000) Large-scale production of recombinant hepatitis $\mathrm{B}$ surface antigen from Pichia pastoris. Biotechnol 77(2-3):157-167

Heitz F, Morris MC, Divita G (2009) Twenty years of cell-penetrating peptides: from molecular mechanisms to therapeutics. Br J Pharmacol 157:195-206

Iglesias E, Franch O, Carrazana Y, Lobaina Y, Garcia D, Sanchez J, Garcia J, Urquiza D, Muzio V, Guillen G, Aguilar JC (2006) Influence of aluminum-based adjuvant on the immune response to multiantigenic formulation. Viral Immunol 19(4):712-721. https://doi.org/10.1089/vim.2006.0038

Iglesias E (2018) Safety assessment of the vaccine candidate TERAVAC-HIV-1 in a phase I therapeutic clinical trial. Oral Presentation at IV International Workshop Infectious Diseases. Varadero, Cuba

Jiang J (2021) Cell-penetrating peptide-mediated nanovaccine delivery. Curr Drug Targets 22(8):896-912. https://doi.org/10.2174/13894 50122666210203193225

Johansson EL, Wassen L, Holmgren J, Jertborn M, Rudin A (2001) Nasal and vaginal vaccinations have differential effects on antibody responses in vaginal and cervical secretions in humans. Infect Immun 69:7481-7486

Kraehenbuhl JP, Neutra MR (2013) Mucosal vaccines: where do we stand? Curr Top Med Chem 13:2609-2628

Lobaina Y (2019) Nasal route for vaccine and drug delivery: features and current opportunities. Int J Pharm 572:118813

Lobaina Y, Michel ML (2017) Chronic hepatitis B: immunological profile and current therapeutic vaccines in clinical trials. Vaccine 35:2308-2314

Lobaina Y, Palenzuela D, Pichardo D, Muzio V, Guillen G, Aguilar JC (2005) Immunological characterization of two hepatitis B core antigen variants and their immunoenhancing effect on codelivered hepatitis B surface antigen. Mol Immunol 42:289-294

Lobaina Y, Trujillo H, Garcia D, Gambe A, Chacon Y et al (2010) The effect of the parenteral route of administration on the immune 
response to simultaneous nasal-parenteral immunizations using a new HBV therapeutic vaccine candidate. Viral Immunol 23(5):521-529

Madani F, Lindberg S, Langel U, Futaki S, Graslund A (2011) Mechanisms of cellular uptake of cell-penetrating peptides. J Biophys. https://doi.org/10.1155/2011/414729

Marasini N, Skwarczynski M, Toth I (2017) Intranasal delivery of nanoparticle-based vaccines. Ther Deliv 8(3):151-167

Muto K, Kamei N, Yoshida M, Takayama K, Takeda-Morishita M (2016) Cell-penetrating peptide penetratin as a potential tool for developing effective nasal vaccination systems. J Pharm Sci 105:2014-2017

Nizard M, Diniz MO, Roussel H, Tran T, Ferreira LCS, Badoual C, Tartour E (2014) Novel strategies and applications for the control of pathogens and tumors at mucosal sites. Hum Vaccin Immunother 10(8):2175-2187

Nizard M, Roussel H, Diniz MO, Karaki S, Tran T et al (2017) Induction of resident memory $\mathrm{T}$ cells enhances the efficacy of cancer vaccine. Nat Commun 8:15221. https://doi.org/10.1038/ncomm s15221

Rosenthal KL, Jeyanathan M, Xing Z (2015) Chapter 66-Filling the immunological gap: recombinant viral vectors for mucosal vaccines. Mucosal Immunol, 4th edn. Vol 2, pp 1291-1306

Rostami B, Irani S, Bolhassani A, Cohan RA (2018) M918: a novel cell penetrating peptide for effective delivery of HIV-1 Nef and Hsp20-Nef proteins into eukaryotic cell lines. Curr HIV Res $16: 280-287$

Russell MW, Moldoveanu Z, Ogra PL, Mestecky J (2020) Mucosal immunity in COVID-19: a neglected but critical aspect of SARSCoV-2 infection. Front Immunol 11:611337. https://doi.org/10. 3389/fimmu.2020.611337

Sahay B, Aranyos AM, Mishra M, McAvoy AC, Martin MM, Pu R, Shiomitsu S, Shiomitsu K, Dark MJ, Sanou MP, Roff SR, Rathore MH, Yamamoto JK (2019) Immunogenicity and efficacy of a novel multi-antigenic peptide vaccine based on cross-reactivity between feline and human immunodeficiency viruses. Viruses 11:136. https://doi.org/10.3390/v11020136

Sakuma S, Suita M, Inoue S, Marui Y, Nishida K et al (2012) Cellpenetrating peptide-linked polymers as carriers for mucosal vaccine delivery. Mol Pharm 9(10):2933-2941

Sandoval F, Terme M, Nizard M, Badoual C, Bureau MF et al (2013) Mucosal imprinting of vaccine-induced CD8+ T Cells is crucial to inhibit the growth of mucosal tumors. Sci Transl Med 5:172

Sarduy MR, García I, Coca MA, Perera A, Torres LA et al (2015) Optimizing CIGB-300 intralesional delivery in locally advanced cervical cancer. Br J Cancer 112:1636-1643
Schirmbeck R, Wild J, Reimann J (1998) Similar as well as distinct MHC class I-binding peptides are generated by exogenous and endogenous processing of hepatitis B virus surface antigen. Eur J Immunol 28:4149-4161

Snapper CM, Paul WE (1987) Interferon- $\gamma$ and B cell stimulatory factor-1 reciprocally regulate Ig isotype production. Science 236:944-947

Tang J, Yin R, Tian Y, Huang Z, Shi J, Fu X, Wang L, Wu Y, Hao F, Ni B (2012) A novel self-assembled nanoparticle vaccine with HIV-1 tat(49 57)/HPV e7(49-57) fusion peptide and GM-CSF DNA elicits potent and prolonged CD8(+) t cell-dependent antitumor immunity in mice. Vaccine 30(6):1071-1082

Thoren PEG, Persson D, Isakson P, Goksor M, Onfelt A, Norden B (2003) Uptake of analogs of penetratin, Tat (48-60) and oligoarginine in live cells. Biochem Biophys Res Commun 307(1):100-107

Thorstensson R, Trollfors B, Al-Tawil N, Jahnmatz M, Bergström J et al (2014) A phase I clinical study of a live attenuated Bordetella pertussis vaccine-BPZE1; a single centre, double-blind, Placebocontrolled, dose-escalating study of BPZE1 given intranasally to healthy adult male volunteers. PLoS ONE 9(1):3449

Tripathi PP, Arami H, Banga I, Gupta J, Gandhi S (2018) Cell penetrating peptides in preclinical and clinical cancer diagnosis and therapy. Oncotarget 9(98):37252-37267

Vallespi MG, Glaria LA, Reyes O, Garay HE, Ferrero J, Araña MJ (2000) A Limulus antilipopolysaccharide factor-derived peptide exhibits a new immunological activity with potential applicability in infectious diseases. Clinical and Diagnostic Laboratory Immunol 7(4):669-675

Vives E, Brodin P, Lebleu B (1997) A truncated HIV-1 Tat protein basic domain rapidly translocates through the plasma membrane and accumulates in the cell nucleus. J Biol Chem 272:16010-16017

Yang J, Luo Y, Shibu MA, Toth I, Skwarczynski M (2019) Cell-penetrating peptides: efficient vectors for vaccine delivery. Curr Drug Deliv 16:430-443

Yang J, Firdaus F, Azuar A, Khalil ZG, Marasini N, Capon RJ, Hussein WM, Toth I, Skwarczynski M (2021) Cell-penetrating peptidesbased liposomal delivery system enhanced immunogenicity of peptide-based vaccine against Group A Streptococcus. Vaccines 9:499. https://doi.org/10.3390/vaccines9050499

Ziegler A (2008) Thermodynamic studies and binding mechanisms of cell-penetrating peptides with lipids and glycosaminoglycans. Adv Drug Deliv Rev 60(4-5):580-597

Publisher's Note Springer Nature remains neutral with regard to jurisdictional claims in published maps and institutional affiliations.

\section{Authors and Affiliations}

\section{Yadira Lobaina $^{1,5}$ (1) Dioslaida Urquiza ${ }^{2} \cdot$ Hilda Garay $^{3} \cdot$ Yasser Perera $^{4,5} \cdot$ Ke Yang $^{5}$}

Yadira Lobaina

yadira.lobaina@cigb.edu.cu; ylobainamato@ccbjic.com

Ke Yang

young@ccbjic.com

1 Biomedical Research Division, Vaccine Department, Center for Genetic Engineering and Biotechnology (CIGB), 10600 Havana, Cuba

2 Animal Facilities, Center for Genetic Engineering and Biotechnology, 10600 Havana, Cuba
3 Biomedical Research Division, Peptide Synthesis Lab, Center for Genetic Engineering and Biotechnology, 10600 Havana, Cuba

4 Biomedical Research Division, Pharmaceutical Department, Molecular Oncology Group, Center for Genetic Engineering and Biotechnology, 10600 Havana, Cuba

5 China-Cuba Biotechnology Joint Innovation Center (CCBJIC), Yongzhou Zhong Gu Biotechnology Co., Ltd, Lengshuitan District, Yongzhou City 425000, Hunan Province, China 